\title{
A TEMÁTICA DA SUSTENTABILIDADE SOCIOAMBIENTAL NOS CURSOS DE LICENCIATURA DO IFC: UMA LEITURA DOS PROJETOS PEDAGÓGICOS
}

\section{ENVIRONMENTAL SUSTAINABILITY THEMES IN IFC'S DEGREE COURSES: A READING OF PEDAGOGICAL PROJECTS}

\author{
MELO, Marilândes Mól Ribeiro de \\ marilandes.melo@ifc-araquari.edu.br \\ IFC - Instituto Federal Catarinense - Campus Araquari \\ SILVA, Filomena Lucia Gossler Rodrigues da \\ filomena@ifc-camboriu.edu.br \\ IFC - Instituto Federal Catarinense - Campus Camboriú \\ SCHEIBE, Leda \\ Ischeibe@uol.com.br \\ UNOESC - Universidade do Oeste de Santa Catarina
}

RESUMO Este artigo analisa ideias de educação e sustentabilidade socioambiental presentes nos projetos pedagógicos dos cursos de licenciatura em Pedagogia, Matemática, Física, Química e Ciências Agrícolas do Instituto Federal Catarinense. Tal estudo visa compreender como a ideia de educação e sustentabilidade é apresentada por eles. Identificou-se que educação está associada à ideia de construção de uma sociedade democrática, inclusiva, ambientalmente equilibrada e promotora de uma convivência responsável, da diversidade cultural, do pensamento crítico e da ética das relações. Já a sustentabilidade pode ser traduzida pelas práticas sociais e dialógicas, reforçando um sentimento de corresponsabilidade por uma sociedade mais justa e de constituição de valores éticos, ambientais, culturais e sociais nas relações cotidianas.

Palavras-chave: Currículo. Instituto Federal Catarinense. Licenciaturas. Sustentabilidade Socioambiental.

ABSTRACT This article analyzes ideas of education and environmental sustainability present in the pedagogical projects of the teacher training courses in Pedagogy, Mathematics, Physics, Chemistry and Agricultural Sciences of the Instituto Federal Catarinense. This analysis aims at an idea of education and sustainability. We have identified that education is associated with the idea of build a democratic, inclusive, environmentally balanced society that promotes responsible coexistence, cultural diversity, critical thinking and ethics in the relationships. Sustainability can be translated into social and dialogic practices, reinforcing a sense of co-responsibility for a fairer society and the constitution of ethical, environmental, cultural and social values in everyday relationships.

Keywords: Curriculum. Instituto Federal Catarinense. Teacher training. Environmental Sustainability. 


\section{INSTITUTO FEDERAL CATARINENSE: CAMPO DE FORMAÇÃO PARA AS LICENCIATURAS}

O tipo de vida, educação e sociedade que teremos no futuro vão depender da qualidade, profundidade e extensão dos processos de aprendizado que formos capazes de criar e exercitar individual e socialmente. (LIMA, 2003, p. 116).

O Instituto Federal Catarinense (IFC), criado pela Lei $11.892 / 2008^{1}$, origina-se da integração das escolas agrotécnicas de Concórdia, Rio do Sul e Sombrio e dos colégios agrícolas vinculados à Universidade Federal de Santa Catarina (UFSC). A instituição oferece cursos que atendem ao proposto no art. $7^{\circ}$ da referida lei, sendo: educação profissional técnica de nível médio; formação inicial e continuada de trabalhadores; ensino superior (licenciaturas, programas especiais de formação pedagógica, formação de tecnólogos, bacharelados e engenharias) e pós-graduação lato e stricto sensu. Importa destacar que, conforme o art. $8^{\circ}$ da lei em questão, pelo menos $20 \%$ das vagas devem ser destinadas às licenciaturas e aos programas especiais de formação pedagógica. A instituição tem como missão "proporcionar educação profissional atuando em ensino, pesquisa e extensão comprometidos com a formação cidadã, a inclusão social e o desenvolvimento regional", e a visão de "ser referência em educação profissional, científica e tecnológica em Santa Catarina" (IFC, 2014a, p. 12).

Atualmente, o IFC é composto por 15 campi, localizados nas cidades de Abelardo Luz (02), Araquari (03), Blumenau (04), Brusque (05), Camboriú (06), Concórdia (07), Fraiburgo (08), Ibirama (09), Luzerna (10), Rio do Sul (11), Santa Rosa do Sul (12), São Bento do Sul (13), São Francisco do Sul (14), Sombrio (15) e Videira (16), uma Unidade Urbana em Rio do Sul, além da Reitoria (01), cuja sede se localiza na cidade de Blumenau, conforme demonstra a figura 1, abaixo:

\footnotetext{
1 Institui a Rede Federal de Educação Profissional, Científica e Tecnológica, cria os Institutos Federais de Educação, Ciência e Tecnologia, e dá outras providências.
} 
Figura 1 - Localização dos campi e da Reitoria do IFC.

\section{Instituto Federal Catarinense}

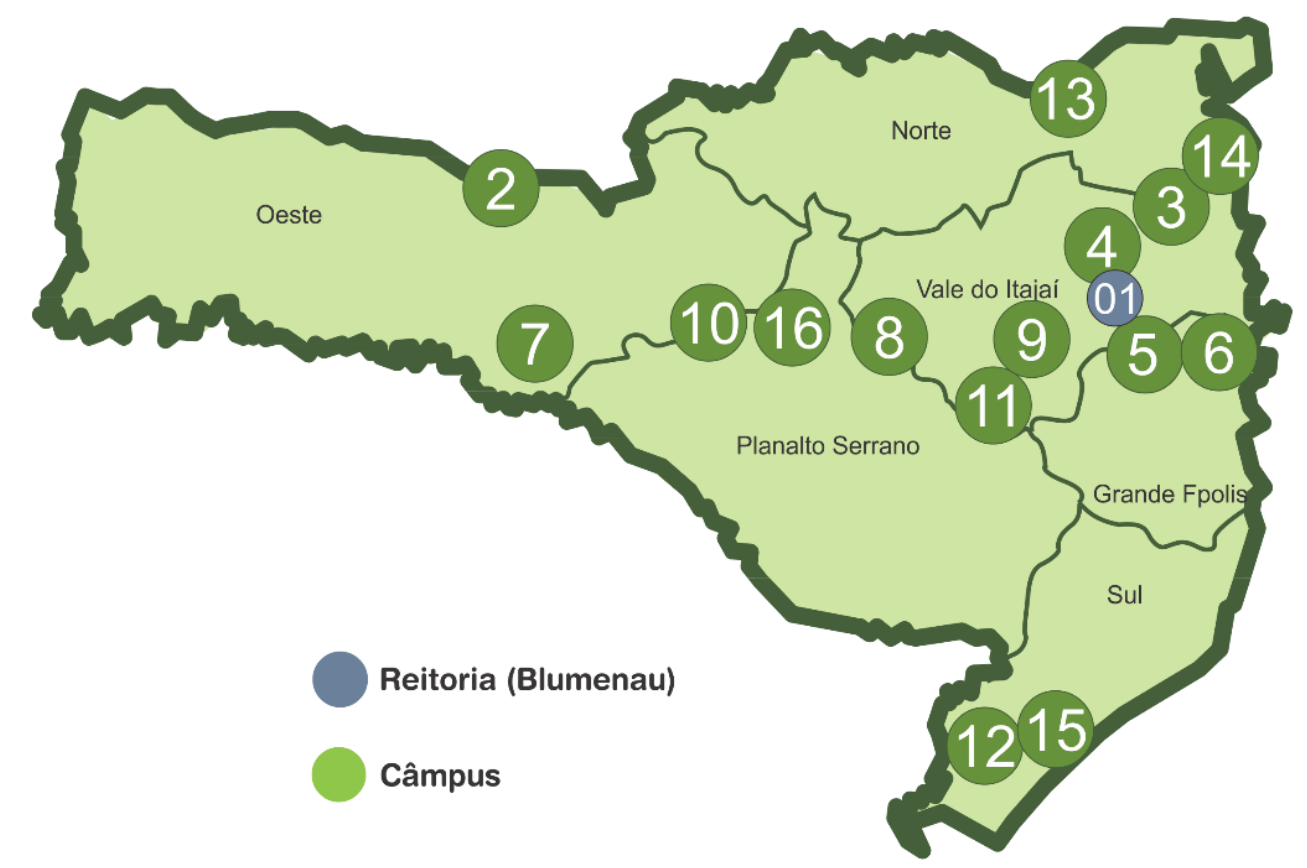

Fonte: http://ifc.edu.br/nossos-campus/

A expansão da Rede Federal de Educação Profissional e Tecnológica em Santa Catarina vem promovendo mudanças significativas no que se refere à ampliação das possibilidades de construção de uma nova realidade para jovens catarinenses. Tal expansão, além de possibilitar a criação de novos cursos técnicos e de qualificação profissional de curta duração, também vem ampliando a oferta de formação em nível superior, com cursos de tecnologia, bacharelado e licenciaturas, e de pós-graduação lato e stricto sensu, considerando as necessidades e especificidades regionais, ou seja, os arranjos produtivos locais, baseados tanto nas tendências sociais quanto do mundo do trabalho, sistematizadas no Projeto Pedagógico Institucional do Instituto Federal Catarinense. Assim:

Com a implementação de ações em favor da melhoria da educação, expressas por meio do ACORDO DE METAS, o IFC atende ao compromisso de oferecer vagas para cursos técnicos - pelo menos $50 \%$; de manutenção das vagas de formação de professores e licenciaturas - pelo menos $20 \%$; de ofertar vagas para PROEJA, FIC, entre outros. Isso tudo tendo como perspectiva promover a inclusão e atender a demanda regional, bem como o disposto na Lei 11.892/2008. (IFC, 2014a, p, 16 - grifos no original).

Segundo consta no PDI (IFC, 2014a, p. 43), os cursos de licenciatura são assim organizados: 
Desenho curricular flexível, tendo os componentes práticos integrados aos conteúdos teóricos por meio do emprego de ambientes de aprendizagem e de projetos integradores, interdisciplinares, estruturados com base curricular comum às áreas de conhecimento e com forte embasamento na práxis associada à educação profissional.

Objetiva-se que o Instituto Federal Catarinense responda, com mais agilidade e eficiência, às demandas crescentes na formação de recursos humanos e na difusão e construção de conhecimentos científicos. Em que pese a formação de professores da Educação Básica, tendo como referência o estabelecido pela Lei 11.892/2008, o IFC vem ofertando os seguintes cursos de Licenciatura: em Física (Campus Rio do Sul), Matemática (Campus Rio do Sul, Camboriú, Concórdia e Sombrio), Química (Campus Araquari), Pedagogia (Campus Blumenau, Camboriú, Rio do Sul e Videira) e Ciências Agrícolas (Campus Araquari).

A oferta de cursos de licenciatura pelos Institutos Federais vem se mostrando como uma oportunidade e possibilidade de formação de professores em instituições públicas de ensino, visando minimizar a carência de profissionais formados para atuar especialmente nos anos finais do Ensino Fundamental e no Ensino Médio. Os cursos de Licenciatura, de acordo com Freire e Campos (2008), no caso brasileiro foram criados na metade da década de 1930, com a seguinte preocupação:

Regulamentação para o preparo de docentes para a escola secundária. Desde sua criação até 0 momento esses cursos de formação de professores foram influenciados pela implantação de diferentes leis e resoluções que alteraram suas estruturas curriculares. (FREIRE; CAMPOS, 2008, p. 1522/1523).

Ao analisarem os cursos de licenciatura, Lüdke e Cruz (2005, p. 93) assinalam que eles "têm sido objeto de intensos debates no cenário educacional, tendo em vista as limitações que cercam sua estruturação". As pesquisadoras argumentam, ainda:

Uma crítica bastante recorrente é a que se refere à estrutura $3+1$, que reforça o predomínio da formação dos conteúdos em relação à formação pedagógica, provocando a separação entre as duas dimensões e, geralmente, considerando a licenciatura como um apêndice do bacharelado. Essa dinâmica revela sinais do modelo da racionalidade técnica, predominante na organização dos currículos de formação de professores. Sob o ponto de vista dessa racionalidade, calcada na separação entre teoria e prática e na supervalorização da área do conhecimento específico que se vai ensinar, a solução para os problemas que perpassam a ação docente está posta pela teoria, bastando, simplesmente, a sua aplicação. O currículo dos cursos de formação organizados nessa perspectiva apresenta, geralmente, uma ciência básica, uma ciência aplicada e, finalmente, um 
espaço de ensino prático, no qual se espera que os alunos aprendam a aplicar o conhecimento adquirido aos problemas da prática cotidiana. (LÜDKE; CRUZ, 2005, p. 93).

Associa-se a esse debate a crescente preocupação demonstrada no país a respeito da formação dos professores, o que pode ser evidenciada nas atuais políticas educacionais. A Lei n. 13.005, de 25 de junho de 2014 (BRASIL, 2014), que aprovou o Plano Nacional de Educação ora em vigência (PNE- 2014/2024), define em quatro metas (15 a 18) estratégias especificamente direcionadas aos profissionais do magistério da Educação Básica, visando à melhoria da sua formação, salário e carreira. Destaque-se também a Resolução CNE/CP no 02 de 2015 (BRASIL, 2015), que redefiniu as Diretrizes Curriculares Nacionais para a Formação Inicial em Nível Superior (cursos de licenciatura, cursos de formação pedagógica para graduados e cursos de segunda licenciatura) e para a Formação Continuada.

As discussões que se estabeleceram no processo de definição dessas normas evidenciaram o quanto as políticas de formação docente trazem à tona conflitos subjacentes à área educacional e oportunizam a percepção da complexidade das relações que se estabelecem entre a ação pública e as demandas sociais. Essa Resolução enfatizou a competência das instituições formadoras de construir/definir seu projeto institucional de formação, o que implica articulações com os sistemas e redes de ensino e com as instituições de Educação Básica, além das demais instâncias envolvidas no trabalho educativo.

Tal problemática associa-se, portanto, à superação da dicotomia entre a teoria e a prática na formação de professores. Pesquisadores como Vasquez (1968), Silva (2010), Saviani (1996), dentre outros, contribuem para a compreensão da necessidade da relação entre a teoria e a prática, visando ao fortalecimento desse processo e à busca de uma Educação Básica referenciada à qualidade social. Para tanto, o debate acerca da sustentabilidade socioambiental, entre outras temáticas, vem adquirindo um espaço essencial, assegurado em documentos importantes para a constituição das políticas educacionais brasileiras, tais como, a título de ilustração, o documento final da Conferência Nacional de Educação - Conae 2014, no qual a expressão "sustentabilidade socioambiental" aparece 17 vezes, possuindo relação direta com a ideia de melhoria da qualidade de vida no planeta. 
Identificada tal relevância, O IFC, por meio da Resolução № 006 CONSUPER/2014, regulamentou as atividades dos Núcleos de Gestão Ambiental (NGA), ligados à Pró-Reitoria de Administração, na Reitoria, e à Direção Geral nos campi. Esses núcleos funcionam como "órgãos colegiados com finalidade consultiva e de apoio para auxiliar na execução das políticas ambientais institucionais" (IFC, 2014a, p. 82). No documento Projeto de Desenvolvimento Institucional (PDI), o IFC defende o princípio da sustentabilidade socioambiental "como um valor fundamental para a comunidade institucional e escolar, que visa melhoria social, ambiental e econômica crescente, bem como auxilia na formação cultural de cidadãos conscientes e ativos" (IFC, 2014a, p. 83).

Considerando o exposto, este texto se propõe a analisar em que medida, nos Projetos Pedagógicos dos cursos de licenciatura (PPCS) ofertados pelo IFC, a sustentabilidade socioambiental ganha projeção e como orienta que os indivíduos, por meio de práticas sociais e dialógicas, reforcem seu sentimento de corresponsabilidade por uma sociedade mais justa e de constituição de valores éticos, culturais e sociais nas relações cotidianas.

Analisamos 14 PPCSs objetivando desvelar se e como podem ser lidas ideias de sustentabilidade. Metodologicamente, optamos por organizar as análises da seguinte forma: os PPCSs dos cursos de Pedagogia e Matemática foram agrupados, considerando que são ofertados em mais de um campus; os dos demais cursos (Física, Química e Ciências Agrícolas) foram analisados em separado por serem ofertados em um único campus. As questões que orientaram as análises são: a compreensão da ideia de educação manifestada nos PPCSs e as implicações entre educação e sustentabilidade que aparecem nesses documentos.

\section{SUSTENTABILIDADE: IDEIAS GERAIS}

Pensar a sustentabilidade de modo mais amplo, de acordo com as argumentações de Lima (2003), é antes de tudo pensar em um modelo de desenvolvimento: é inserir o tema na pauta de um discurso de expressão dominante, relacionado com o meio ambiente e com o desenvolvimento social em sentido amplo. 
Scheibe e Buss (1993) argumentam que é preciso pensar os problemas ambientais e a sustentabilidade sob a ótica da qualidade de vida no contexto do espaço natural e social. A civilização do ser e da distribuição do ter está colocada em suas análises em contraposição a uma sociedade que adota um modelo de desenvolvimento que des-envolve, isto é, que não pode ser francamente compartilhado, que não envolve, mas segrega.

Para Lima (2003, p. 99), em pouco tempo, "sustentabilidade tornou-se palavra mágica, pronunciada indistintamente por diferentes sujeitos, nos mais diversos contextos sociais e assumindo múltiplos sentidos". Diegues (1992, p. 22, grifos no original) assinala:

Esse termo [sustentabilidade] transita pelos mais diversos círculos e grupos sociais, desde as organizações não-governamentais até as de pesquisa, com notável e estranho consenso [...] Uma análise mais aprofundada revela uma falta de consenso, não somente quanto ao adjetivo 'sustentável', como também quanto ao desgastado conceito de 'desenvolvimento'.

O mesmo autor (1992, p. 28) defende a noção de "sociedades sustentáveis" em detrimento de um "desenvolvimento sustentável". Argumenta ele que a ideia primeira "possibilita a cada uma delas definir seus padrões de produção e consumo, bem como o de bem-estar a partir de sua cultura, de seu desenvolvimento histórico e de seu ambiente natural". Ribeiro (1991, p. 75), por sua vez, afirma que desenvolvimento sustentável é "uma noção que ainda não está completamente construída, nem é totalmente operacional". Passadas duas décadas, percebemos que essa noção continua não consensual e entendida em sua amplitude, considerando-se a complexificação da sociedade e a restrição da relação do termo ao ambiente natural, não alcançando a compreensão da sustentabilidade social.

A noção de "sociedades sustentáveis" tem deixado sua marca entre os mais distintos campos do conhecimento e dos mais diversos fazeres. Assim, pensar a sustentabilidade traz também implicações ao campo educacional e ao processo educativo. Lima (2003) assinala, ainda, que essas implicações podem ser percebidas nas:

[...] políticas públicas dirigidas à educação, ambiente e desenvolvimento de alguns países, uma tendência a substituir a concepção de educação ambiental, até então dominante, por uma nova proposta de 'educação para a sustentabilidade' ou 'para um futuro sustentável'. (LIMA, 2003, p. 99, grifos no original). 
O mesmo autor demonstra, ainda, que esse é um discurso que emergiu como substituto ao discurso do desenvolvimento econômico e que as "expressões mais recentes sobre a sustentabilidade talvez possam ser observadas nos princípios da década de 70 do século passado" (LIMA, 2003, p. 101). Lima analisa também a emergência da noção de ecodesenvolvimento, formulada pelo economista Ignacy Sachs e que, posteriormente, deu projeção ao termo "desenvolvimento sustentável", por meio da Comissão Brundtland"2; matriz que detém o discurso hegemônico sobre sustentabilidade. Nas análises realizadas por Lima (2003), o que se destaca no pensamento de Sachs são as ideias de direitos, de desigualdades sociais, de autonomia dos povos e nações desfavorecidos na ordem mundial. Diegues (1992, p. 22), ao analisar a ideia de sustentabilidade, afirma: "desenvolvimento sustentado é hoje um termo utilizado ad nauseam sobretudo nos discursos governamentais e nos preâmbulos de projetos de investimentos a serem financiados por instituições financeiras bi e multilaterais".

Scheibe (2004, p. 326) assinala que tanto as ideias de ecodesenvolvimento como de desenvolvimento sustentável precisam ser tensionadas e, inspirada em Ignacy Sachs, aborda as cinco dimensões da sustentabilidade, a saber: sustentabilidade social, econômica, ecológica, espacial e cultural, que indicam tanto aspectos utópicos, quanto orientadores de "caminhos para uma melhoria gradativa de aspectos das relações homem-natureza".

Scheibe (2004, p. 332) classifica o desenvolvimento sustentável como "uma ideia equívoca para alcançar seus objetivos, ao revitalizar o velho mito desenvolvimentista, promovendo a falácia de um crescimento econômico sustentável sobre a natureza limitada do Planeta". Já sobre a sustentabilidade, afirma que precisa ser "fundada no reconhecimento e limites potenciais da natureza, assim como a complexidade ambiental, inspirando uma nova compreensão do mundo para enfrentar os desafios da humanidade" (SCHEIBE, 2004, p. 332).

\footnotetext{
2 Esse discurso, de acordo com Lima (2003, p. 108), "enfatiza a dimensão econômica e tecnológica da sustentabilidade e entende que a economia de mercado é capaz de liderar o processo de transição para o desenvolvimento sustentável, através da introdução de 'tecnologias limpas', da contenção do crescimento populacional e do incentivo a processos de produção e consumo ecologicamente orientados". Agrega consigo a ideia de Modernização Ecológica e desenvolvimento sustentável.
} 
Os estudiosos do fenômeno percebem que há uma forte renovação discursiva, orientada especialmente pelos países centro europeus e disseminada por organismos internacionais como, por exemplo, a Organização das Nações Unidas para a Educação, a Ciência e a Cultura (Unesco). É uma disputa pela "compreensão legítima" do significado de sustentabilidade e faz parte de um ambiente no qual "gravitam múltiplas e diversas forças sociais, interesses e leituras que disputam entre si o reconhecimento e a legitimação social" (LIMA, 2003, p. 100).

Assim, a busca pela construção de uma verdade para a apropriação social desmascara a noção de neutralidade e desinteresse na construção do conceito de sustentabilidade, uma vez que há sempre um desejo de poder e de dominação. Carvalho (1991) já denunciou alguns desses pontos de vista colocados desde 1972, na Conferência de Estocolmo:

\begin{abstract}
[...] ficou claro que a preocupação dos organismos internacionais quanto ao meio ambiente era produzir uma estratégia de gestão desse ambiente, em escala mundial, que entendesse a sua preservação dentro de um projeto desenvolvimentista. Dentro dessa perspectiva produtivista, o que se queria preservar de fato era um modelo de acumulação de riquezas onde 0 patrimônio natural passava a ser um bem. $\mathrm{O}$ apelo à humanidade e ao bemestar dos povos era usado como álibi, sempre citado ao lado dos objetivos de crescimento econômico, emprestando uma preocupação humanista a intenções não tão nobres. (CARVALHO, 1991, p. 79).
\end{abstract}

Assim, pensar a sustentabilidade constituía-se em um mecanismo apaziguador de conflitos entre nações marcadas por divergências, desigualdades e assimetrias sociais, dentre outras, uma vez que se defende que esse seria um campo comum, no qual imperaria a neutralidade. Lima (2003, p. 104) assinala, por exemplo, que esse "campo comum e genérico da sustentabilidade permitiu aproximar capitalistas e socialistas, conservacionistas e ecologistas, antropocêntricos e biocêntricos, empresários e ambientalistas, ONGs, movimentos sociais e agências governamentais".

Para além desse "território neutro", Lima (2003, p. 105) adverte, no entanto, que a ideia de sustentabilidade passa pela compreensão de "uma proposta de reestruturação da economia política do capitalismo que se esforça em demonstrar a compatibilidade entre crescimento econômico e proteção ambiental, e a possibilidade de enfrentar a crise ambiental dentro dos marcos do capitalismo". Jacobi $(2003$, p.193) sustenta que a "problemática da sustentabilidade assume neste 
novo século um papel central na reflexão sobre as dimensões do desenvolvimento e das alternativas que se configuram".

Podemos considerar que as ideias de sustentabilidade desse pesquisador estão relacionadas aos pensamentos desenvolvidos sobre uma defesa de sustentabilidade que se levanta contra 0 discurso politicamente pragmático e hegemônico: de acordo (LIMA, 2003, p. 108) esse é "um contradiscurso à versão oficial e pode ser entendida [a sustentabilidade] como uma concepção complexa ou multidimensional de sustentabilidade que tenta integrar o conjunto de dimensões da vida individual e social". (LIMA, 2003, p. 108). Jacobi (2003, p.193) afirma ainda sobre tais ideias:

Tem como pressuposto a existência de sustentabilidade social, econômica e ecológica. Estas dimensões explicitam a necessidade de tornar compatível a melhoria nos níveis e qualidade de vida com a preservação ambiental. Surge para dar uma resposta à necessidade de harmonizar os processos ambientais com os socioeconômicos, maximizando a produção dos ecossistemas para favorecer as necessidades humanas presentes e futuras.

\section{IDEIAS DE EDUCAÇÃO E SUSTENTABILIDADE NOS PPCSs NOS CURSOS DE LICENCIATURA DO IFC}

A análise dos Projetos Políticos Pedagógicos dos Cursos Superiores (PPCS) de Licenciatura do IFC, aqui proposta, visa conhecer as direções que têm orientado a adoção da ideia de sustentabilidade e das relações estabelecidas com a educação. Dessa maneira, retomamos as interrogações lançadas no início deste artigo e com as quais procuraremos dialogar.

É preciso, para isso, entender a ideia de educação defendida nesses projetos de curso, os seus objetivos, os valores que os orientam, o público ao qual se destinam, bem como as forças que regem o campo educacional, que em sua atual conjuntura está dominado pelo instrumentalismo e utilitarismo, tanto das práticas quanto das políticas educacionais, pois fundamentado em um "modelo pragmático de educação orientado pelas demandas da economia, que tende a priorizar a profissionalização para o mercado de trabalho e valores relacionados à eficiência, controle de qualidade e competitividade" (LIMA, 2003, p. 112). Mesmo nesse contexto, debruçamo-nos sobre os princípios filosóficos dos Projetos Pedagógicos dos cursos de licenciatura do IFC, objetivando encontrar elementos que sustentam a 
ideia de sustentabilidade socioambiental a partir da concepção de educação neles presente.

Nos princípios filosóficos e pedagógicos do curso de Licenciatura em Ciências Agrícolas, a ideia de educação que pode ser lida está relacionada à construção de uma perspectiva democrática, considerando que se propõe a formar "sujeitos ativos e participantes na construção de uma sociedade participativa capaz de proceder aos julgamentos éticos dos processos econômicos e sociais" (IFC, 2013b, p. 10). O PPCS desse curso destaca também a ideia de educação das consciências que orientam os agentes a organizarem seus meios materiais e elaborar planos de ação que podem conduzir às transformações das realidades sociais. A ideia de educação das consciências, contida nos PPCSs, nos remete ao desejo de apagamento da "sombra da opressão", termo utilizado por Paulo Freire para entender a massificação humana. Para Freire (1967, p. 37), "expulsar esta sombra pela conscientização é uma das fundamentais tarefas de uma educação realmente liberadora e por isto respeitadora do homem como pessoa".

O PPCS do curso Licenciatura em Química revela uma concepção de educação comprometida "com o desenvolvimento de uma sociedade democrática, inclusiva e ambientalmente equilibrada" (IFC, 2014b, p. 17) e que construa um caráter de cidadania autônoma, reflexiva, ética, solidária, responsável e estimuladora da busca pelo conhecimento, como aspectos integradores que enraízam o humano em seu contexto e não apenas o acomoda ou ajusta. Freire (1967, p. 41-42) argumenta que estar integrado ao contexto implica:

\footnotetext{
Estar não apenas nele, mas com ele, e não a simples adaptação, acomodação ou ajustamento, comportamento próprio da esfera dos contatos, ou sintoma de sua desumanização, implica em que, tanto a visão de si mesmo, como a do mundo, não podem absolutizar-se, fazendo-o sentir-se um ser desgarrado e suspenso [...]. A sua integração o enraíza.
}

Os PPCSs do curso de Licenciatura em Pedagogia de todos os campi do IFC que o ofertam contêm muitos aspectos semelhantes quanto à ideia de educação (Blumenau, Camboriú, Rio do Sul, Videira). Em sua primeira versão (ano 2014), no campus Blumenau a ideia é que se realize uma educação que vise à "transformação social e que reflita criticamente acerca dos espaços escolares e do fazer docente" (IFC, 2014c, p. 12). 
A ideia ancora uma formação de professores de qualidade, o que se daria pela indissociabilidade entre ensino, pesquisa e extensão e pela orientação para a superação do caráter tecnicista de formação. Segundo o PPCS, estaria estatisticamente comprovada a carência de formação de professores(as) em nível superior nas regiões de oferta dos cursos, bem como o aumento crescente da demanda, considerando que o número de matrículas para a educação básica tem aumentado significativamente. Em sua segunda versão (ano 2015d), essas características permaneceram, e as principais mudanças realizadas dizem respeito à alteração de carga horária, nome e semestre de oferta na matriz curricular das unidades curriculares da Psicologia, da Linguística e dos Fundamentos metodológicos.

Os PPCSs dos cursos de Pedagogia oferecidos pelos campi Camboriú e Rio do Sul se coadunam com os princípios do campus Blumenau - de educação democrática, de transformação social e de construção da cidadania crítica. Estão agregadas à proposta desses cursos as ideias de diversidade cultural, interdisciplinaridade, inclusão, ética e visão humanística. O PPCS do campus Videira está em sua terceira versão e defende a educação como promotora de uma convivência responsável, do respeito à diversidade, da quebra de barreiras atitudinais, de um pensar crítico, da contextualização, da sensibilidade afetiva e que prioriza a construção do conhecimento em detrimento de sua transmissão.

Os PPCSs dos cursos de licenciatura em Matemática dos campi de Camboriú e Concórdia defendem uma concepção de educação como prática social e plural, o que se pretende por meio da articulação entre os conhecimentos práticos - no aspecto da experimentação e dos contatos com as habilidades exigidas para o exercício da profissão - e teóricos, visando assim a construção da autonomia e o exercício de cidadania dos sujeitos. Defende igualmente que uma boa formação exerce influência no ensino, na aprendizagem e que se estende para a constituição de uma sociedade de qualidade nos mais diversos âmbitos, uma vez que capacita para uma leitura crítica da realidade.

O PPCS do curso de Matemática do campus Rio do Sul, em sua quarta versão, defendia em sua missão a preocupação com um processo formativo que observasse as questões éticas e humanísticas de modo mais amplo. A atual versão (quinta) atualizou tanto a missão quanto a visão do curso: passou a focar em uma 
formação com conhecimentos matemáticos e didático-pedagógicos sólidos, que construam profissionais críticos, criativos e autônomos, capazes que solucionar problemas da realidade.

Possui também como fundamento a concepção de educação como prática social e plural e como produto da construção histórica que visa à justiça social e à diversidade cultural. No campus Sombrio, o PPCS indica que o curso visa oferecer uma educação que capacite uma leitura crítica da realidade, tendo o conhecimento matemático e suas metodologias como bases para a educação promotora da democracia e da cidadania.

Todos os PPCSs analisados enfatizam a necessidade da relação estreita entre teoria e prática. Consideramos que a argumentação sobre essas duas faces da mesma moeda do fazer pedagógico tem em vista que elas contribuem para "transformar a natureza e a sociedade; prática, na medida em que a teoria, como guia das ações, orienta a atividade humana; teórica, na medida em que esta ação é consciente" (VASQUEZ, 1968, p. 117). Todos, igualmente, consideram as condições históricas nas quais as sociedades específicas (das cidades nas quais os campi estão instalados) se construíram, denotando, assim, uma atenção às contradições existentes no atual modo social de produção da vida humana.

A perspectiva de pensar historicamente revelada nos PPCSs dos cursos de licenciatura oferecidos pelo IFC nos permite inferir que vigora uma compreensão da educação como prática de liberdade, uma vez que pensa os agentes como sendo enraizados socialmente, considerando, assim, que "não há educação fora das sociedades humanas e não há homem no vazio" (FREIRE, 1967, p. 35); revela igualmente uma ideia de educação que constitui a sociedade como sujeito de si mesma, reconhecendo o homem e o povo como sujeitos de sua história; ou seja, a educação concebida por Freire (1967, p. 36) como aquela que é "desvestida da roupagem alienada e alienante, seja uma força de mudança e de libertação".

No PPCS do curso de Pedagogia do campus Blumenau (2014c, p. 23) está explícita a ideia da construção do sujeito capaz de promover sua libertação: "o sujeito, da mesma forma que sofre a ação dos fatores sociais, culturais e históricos, também pode agir de forma consciente sobre estas forças". Para cumprir o compromisso de uma educação libertadora, em todos os PPCSs, a opção é pelo processo metodológico de aprendizagem amparado por uma perspectiva histórico- 
cultural. Colocadas as ideias que os cursos possuem sobre educação, como objetivo deste artigo procuramos rastrear a presença da ideia de sustentabilidade nos projetos de curso.

A esse respeito, encontramos no projeto do Curso de Ciências Agrícolas expressões como cumprir "exigências do mercado e/ou mundo do trabalho"; "arranjos produtivos"; "pesquisa aplicada" dentre outros, que sugerem "o predomínio da esfera do mercado na condução da sustentabilidade em detrimento da sociedade civil e do Estado" (LIMA, 2003, p. 106).

Essas ideias, de alguma forma, estão presentes nos PPCSs de todos os cursos analisados, oscilando entre o desejo de justiça social e 0 atendimento das demandas do mercado. Evidentemente que se espera que a formação oferecida permita aos estudantes encontrarem formas de atuação no mundo do trabalho que Ihes proporcionem prover sua existência e subsistência. Entretanto, conforme Lima (2003, p. 106, grifo nosso),

Uma 'sustentabilidade de mercado' não responde igualmente à crise social, já que a racionalidade inerente ao mercado se orienta para a concentração e não para a distribuição de riquezas e oportunidades. [...] o mercado é um eficiente instrumento de alocação de recursos, mas um perverso gestor das disparidades sociais.

A esse respeito, Silva (2014, p. 139) coloca que a ideia de mercado de trabalho "repercute em uma formação voltada ao ensino da técnica, característica que atende as demandas de formação de mão de obra [...], que, de maneira geral, tendo em vista o sistema produtivo em que estamos inseridos, dispensa a formação crítica dos seus "colaboradores". E afirma mais: esse discurso desconsidera "a possibilidade de uma formação crítica e com base científica sólida. Esta concepção repercute, por conseguinte, na construção de uma identidade profissional convergente com tais discursos e políticas".

Por outro lado, há nos documentos analisados expressões como "responsabilidade social e ambiental" e a necessidade de existirem:

Agentes capazes de subsidiar um projeto nacional de desenvolvimento sustentável e socialmente justo (IFC, 2013b, p. 10);

Sujeitos conscientes do seu papel na construção e transformação do meio em que vivem; investigação e reflexão crítica no campo do conhecimento ambiental ecológico; respeito às diferenças de natureza ambientalecológica; e saber processos de ensinar e aprender, em diferentes meios ambiental-ecológicos (IFC, 2014c, p. 22). 
Compreender os problemas socioambientais; relação e implicações entre educação, escola e sociedade/ambiente (IFC, 2013b, p. 22).

Compreender e traduzir as necessidades de indivíduos, grupos sociais e comunidades com relação a problemas sócio-econômico-ambientais (IFC, 2015c, p. 22).

Essas afirmações, ainda que não explicitem de maneira mais verticalizada a ideia de sustentabilidade, indicam uma perspectiva que busca pensar essa concepção distanciada da "sustentabilidade de mercado", argumento orientador tanto de ações quanto dos debates recentes. Nos vieses de justiça, transformação, respeito às diferenças defendidos nos PPCSs, podemos vislumbrar a busca por uma nova ética: "uma perspectiva mais global biocêntrica" (DIEGUES, 1992, p. 27).

No campus Camboriú, o curso de licenciatura em Matemática apresenta um diferencial em relação aos demais: dedica, no PPCS, um subitem exclusivamente para tratar o tema Educação Ambiental. Possivelmente isso se deva ao fato de que, enquanto ainda era Colégio Agrícola de Camboriú (CAC), ofertava um curso técnico na área de conhecimento de Meio Ambiente e que, em 2009, deu lugar ao curso técnico em controle ambiental. Esta noção é assim entendida:

[...] a apropriação dos conceitos científicos, para entender o funcionamento da natureza e sua aplicabilidade em tecnologias, é fundamental para a formação do cidadão responsável, pois o instrumentaliza para tomada de decisões individuais e coletivas nas comunidades. Amadurecer a consciência do uso e do abuso dos recursos naturais, principalmente os não renováveis, questionando a sociedade consumista e mercantilista, também são desejáveis para 0 desenvolvimento da cidadania. As questões ambientais são permeadas pela ciência o tempo todo. Atitudes como separar o lixo, optar pela utilização de formas alternativas e não poluentes de transporte, utilizar recursos energéticos de forma consciente são exemplos de pequenas ações que têm um efeito positivo com relação à consciência da cidadania. (IFC, 2013b, p. 26-27).

A perspectiva contida no documento converge com o que Diegues (1992, p. 27) denomina como uma nova ética que deve propor "novos paradigmas sociais que se confrontam com os atuais". Inspirado no pensamento denominado Ecologia Profunda, Diegues (1992, p. 27) afirma que uma nova ética implica a tomada de algumas atitudes:

[...] harmonia com a natureza, que é constituída por seres vivos com direitos à existência independente de seu valor de uso; objetivos não materiais/sustentabilidade ecológica; recursos finitos; soluções adaptadas a cada situação e ecossistema; necessidade básica/reciclagem; descentralização/pequena escala. 
Assim, no curso de licenciatura em Matemática (campus Camboriú) a educação é o meio pelo qual o curso busca disseminar as ideias sobre o meio ambiente acima destacadas, abordadas essencialmente pelas disciplinas de Políticas Públicas em Educação, Sociologia da Educação, Filosofia, Educação Trabalho e Sociedade e Teorias Educacionais e Curriculares. O PPC ainda sinaliza que tais discussões serão realizadas em eventos como semanas acadêmicas, ciclo de palestras, projetos integrados, entre outros.

O curso de licenciatura em Pedagogia (campus Videira) assinala a existência do Núcleo de Gestão Ambiental (NGA), instância na qual se discute, formula e implementa a Política Ambiental do IFC. De acordo com o PPCS, o princípio de sustentabilidade socioambiental é "um valor fundamental para a comunidade escolar", como também as ações do NGA "estarão voltadas para a aplicação de conhecimentos teóricos e práticos aos problemas ambientais" (IFC, 2013d, p. 259). A forma por excelência de implementação das ações serão os projetos de pesquisa e extensão.

\section{CONSIDERAÇÕES FINAIS}

Este texto se propôs a analisar em que medida as ideias de sustentabilidade socioambiental estão presentes nos cursos de licenciatura do Instituto Federal Catarinense e como elas ganharam projeção nos PPCSs das licenciaturas ofertadas pela instituição. A análise se realizou especialmente a partir das relações entre educação e sustentabilidade. Para tanto, foi necessário compreender a ideia de educação defendida nesses projetos de curso, os seus objetivos e os valores que os orientam.

Observamos que a noção de educação está associada à ideia de construção de uma sociedade democrática, inclusiva, ambientalmente equilibrada e promotora de uma convivência responsável, da diversidade cultural, interdisciplinaridade, do pensamento crítico e da ética das relações. Portanto, uma concepção de educação que pretende formar sujeitos ativos, capazes de exercer a cidadania plena, por meio da reflexão sobre as contradições sociais e almejando a justiça social.

Essa compreensão de educação articula-se com 0 conceito de sustentabilidade socioambiental, que ultrapassa a ideia do natural e alcança a esfera 
do social. Assim, converge com a defesa de uma "civilização do ser e da distribuição do ter", que está presente nas análises e nos diálogos com os autores que contribuíram com as reflexões realizadas neste texto. Tais reflexões consideram pensar uma sociedade que adota um modelo de desenvolvimento que envolve, isto é, que pode ser francamente compartilhado por toda a humanidade e socialmente mais justo.

Ao entender a sustentabilidade nessa perspectiva, pressupomos que a concepção de educação que fundamenta as propostas de formação de professores necessita ser sustentada por uma práxis comprometida com o modelo de sociedade acima exposto.

\section{MARILÂNDES MÓL RIBEIRO DE MELO}

Licenciada em Pedagogia pela Universidade Federal de Santa Catarina (UFSC). Mestre e Doutora em Educação também pela UFSC. Atualmente é professora nos cursos de licenciatura do Instituto Federal Catarinense - Campus Araquari, professora do Programa de Pós-graduação em Educação Lato Sensu do Instituto Federal Catarinense - Campus Camboriú, onde também coordena a linha de Gestão da Educação.

\section{FILOMENA LUCIA GOSSLER RODRIGUES DA SILVA}

Licenciada em Pedagogia pela Universidade do Oeste de Santa Catarina (Unoesc). Mestre em Educação pela mesma instituição. Doutora em Educação pela Universidade Federal de Santa Catarina (UFSC). Atualmente é professora nos cursos de licenciatura e professora e coordenadora do Programa de Pós-graduação em Educação Lato Sensu do Instituto Federal de Educação, Ciência e Tecnologia Catarinense - Campus Camboriú.

\section{LEDA SCHEIBE}

Doutora em Educação pela PUC/SP. Professora Titular Emérita Aposentada da Universidade Federal de Santa Catarina (UFSC). Professora do Programa de PósGraduação em Educação da Universidade do Oeste de Santa Catarina (Unoesc).

\section{REFERÊNCIAS}

BRASIL. Resolução CNE/CP n. 02/2015. Define as Diretrizes Curriculares Nacionais para a formação inicial em nível superior (cursos de licenciatura, cursos de formação pedagógica para graduados e cursos de segunda licenciatura) e para a formação continuada. Diário Oficial da União, Brasília, DF, 2015. 
Lei n. 13.005, de 25 de junho de 2014. Aprova o Plano Nacional de

Educação - PNE e dá outras providências. Diário Oficial da União, Brasília, 2014.

CARVALHO, I. C. Territorialidades em luta: uma análise dos discursos ecológicos.

Série registros, no 9, p. 1-56, São Paulo: Instituto Florestal, Secretaria do Meio Ambiente, 1991.

CONAE -2014. Conferência Nacional de Educação: Documento Final. Fórum Nacional de Educação, Secretaria Executiva Adjunta, 2014.

DIEGUES, A.C. Desenvolvimento sustentável ou sociedades sustentáveis: da crítica dos modelos aos novos paradigmas. São Paulo em Perspectiva, São Paulo, v. 6, n. 1-2, p. 22-29, jan./jun. 1992.

FREIRE, L. I. F.; CAMPOS, S. X. Análise da reestruturação curricular do Curso de Licenciatura em Química da UEPG. VIII CONGRESSO NACIONAL DE EDUCAÇÃO. EDUCERE. III CONGRESSO IBERO - AMERICANO SOBRE VIOLÊNCIAS NAS ESCOLAS - CIAVE. Temática: Formação de Professores. Pontifícia Universidade Católica do Paraná. Anais... Curitiba, 06 a 09 de outubro de 2008. P. 719-743. Disponível em:

<http://www.pucpr.br/eventos/educere/educere2008/anais/index1.html> Acesso em: 21 abr. 2016.

INSTITUTO FEDERAL CATARINENSE. Plano de Desenvolvimento Institucional (PDI). Blumenau, Santa Catarina. 2014a. Disponível em <http://ifc.edu.br/wpcontent/uploads/2014/05/PDI_IFC.pdf>. Acesso em: 13 jul. 2016.

- Projeto Pedagógico de Curso Superior (PPCS). Licenciatura em Matemática. Rio do Sul/SC. Janeiro, 2015a.

Projeto Pedagógico de Curso Superior (PPSS). Licenciatura em Física. Rio do Sul/SC. Agosto, 2015b.

- Projeto Pedagógico de Curso Superior (PPCS). Licenciatura em Pedagogia. Rio do Sul/SC, 2015c.

- Projeto Pedagógico de Curso Superior (PPCS). Licenciatura em Pedagogia. Blumenau/SC, 2015d.

Projeto Pedagógico de Curso Superior (PPCS). Licenciatura em Química. Araquari/SC. Outubro, 2014b.

- Projeto Pedagógico de Curso Superior (PPCS). Licenciatura em Pedagogia. Blumenau/SC. Setembro, 2014c.

- Projeto Pedagógico de Curso Superior (PPCS). Licenciatura em Matemática. Concórdia/SC. Outubro, 2014d. 
- Projeto Pedagógico de Curso Superior (PPCS). Licenciatura em Matemática. Sombrio/SC. Fevereiro, 2014e.

. Projeto Pedagógico de Curso Superior (PPCS). Licenciatura em Matemática. Blumenau/SC. Outubro, 2013a.

- Projeto Pedagógico de Curso Superior (PPCS). Licenciatura em Matemática. Camboriú/SC. Outubro, 2013b

. Projeto Pedagógico de Curso Superior (PPCS). Licenciatura em Ciências Agrícolas. Blumenau/SC. Setembro, 2013c.

$\overline{\text { Pedagogia. Videira/SC. Março, 2013d. }}$

- Projeto Pedagógico de Curso Superior (PPCS). Licenciatura em - Projeto Pedagógico de Curso Superior (PPCS). Licenciatura em Pedagogia. Camboriú/SC. Outubro, 2010.

JACOBI. Educação Ambiental, Cidadania e Sustentabilidade. Cadernos de Pesquisa, n. 118, março/ 2003 Cadernos de Pesquisa, n. 118, p. 189-205, março/ 2003.

LIMA, G. C. O discurso da sustentabilidade e suas implicações para a educação. Ambiente \& Sociedade, v.6, n. 2, p. 145-163, jul./dez. 2003.

LÜDKE, M.; CRUZ, G. B. Aproximando Universidade e escola de educação Básica pela pesquisa. Cadernos de Pesquisa, v. 35, n. 125, p. 81-109, 2005.

RIBEIRO, G. L. Ambientalismo e desenvolvimento sustentado. Nova ideologia/utopia do desenvolvimento. Revista de Antropologia, São Paulo, USP, n. 34, p. 59-101, 1991.

SAVIANI, D. Educação: do senso comum à consciência filosófica. 11. ed. Campinas, SP: Editora Autores Associados, 1996.

SCHEIBE, L. F; BUSS, M.D. Mineração, meio ambiente e caráter paradoxal do conceito de des(-)envolvimento. In: 37을 CONGRESSO BRASILEIRO GEOLOGIA; São Paulo, Anais... Resumos Expandidos; São Paulo: Sociedade Brasileira de Geologia, 1993. p. 607-608.

SCHEIBE, L. F. Desenvolvimento sustentável, desenvolvimento durável. In: ZAKRZEVSKI, S. B.; BARCELOS, V. (Orgs). Educação Ambiental e compromisso social. Pensamentos e ações. Erechim, RS: Edi FAPES, p. 317-335. 2004.

SILVA, F. L. G. R. Identidade profissional dos professores da Educação Profissional Técnica de Nível Médio no Brasil e em Santa Catarina: desafios para a sua formação. 2014. 237 f. Tese (Doutorado em Educação). Programa de Pós-graduação em Educação, Universidade Federal de Santa Catarina (UFSC), Florianópolis, 2014. 
SILVA, A. V. A articulação entre teoria e prática na construção do conhecimento pedagógico do conteúdo. Revista Espaço Acadêmico. v. 10, n. 112, p. 58- 66, set. 2010.

VASQUEZ, A.S. Filosofia da práxis. Rio de Janeiro: Paz e Terra, 1968. 